\title{
Receipt and Sharing of Information to Improve Knowledge About Living Donor Kidney Transplant Among Individuals With Advanced CKD
}

Dinushika Mohottige ( $\sim$ dm26@duke.edu )

Duke University School of Medicine

Clemontina Davenport

Duke University School of Medicine

Hui-Jie Lee

Duke University School of Medicine

Patti Ephraim

Johns Hopkins Bloomberg School of Public Health

Nicole DePasquale

Duke University School of Medicine

Ashley Cabacungan

Duke University School of Medicine

Tyler Barrett

Duke University School of Medicine

Lisa McElroy

Duke University School of Medicine Jane Pendergrast

Duke University School of Medicine

Clarissa J. Diamantidis

Duke University School of Medicine

\section{Ebony Boulware}

Duke University School of Medicine

\section{Research Article}

Keywords: LDKT, patient education, information dissemination, transplant knowledge, CKD

Posted Date: May 26th, 2021

DOI: https://doi.org/10.21203/rs.3.rs-519354/v1 
License: (c) (i) This work is licensed under a Creative Commons Attribution 4.0 International License. Read Full License 


\section{Abstract}

Background: Knowledge about living donor kidney transplant (LDKT) is associated with greater LDKT access. Yet, little is known about factors associated with high LDKT knowledge.

Methods: As part of a clinical trial, we conducted a cross-sectional analysis of data obtained from individuals seen in nephrology clinics who were deemed candidates for pre-emptive LDKT. We assessed participants' LDKT knowledge [10-point scale based on correct answers to questions about prognosis, donation, and financial aspects of LDKT; (high knowledge $\geq 8$ )], self-reported receipt of information about LDKT from various health professionals, and self-reported history of having shared information about LDKT with family members or friends. In multivariable logistic regression models adjusting for participants' age, race, and total household income, we quantified the association of participants' high LDKT knowledge with their receipt of LDKT information from health professionals and their sharing of LDKT information with family/friends.

Results: Among 130 participants, the median (IQR) age was 59.5 (52.0-65.0) years, 60\% were female, $47.7 \%$ were Black or African American, and $49.2 \%$ had a high school education or less. Participants had seen their nephrologists for a median (IQR) of 2.0 (1.0-4.0) years. Over half (55.4\%) had high LDKT knowledge. Nearly one third reported having received LDKT information (33.1\%) or sharing LDKT information with family/friends (28.5\%). After adjustment, those who received (versus did not receive information) and shared information with family/friends had 3-fold higher odds of high LDKT knowledge (3.05 [1.24, 8.08]). Individuals who received LDKT information (versus did not receive information) from health professionals had 4-fold higher odds of high LDKT knowledge (adjusted OR [95\% Cl]: 4.01 [1.49, 12.18].

Conclusions: Both the receipt of LDKT information from health professionals and sharing of LDKT information with family members/friends were associated with high LDKT knowledge. Improved provision of LDKT information to patients with advanced CKD and encouragement to share information with family members or friends could aid efforts to improve LDKT rates.

Trial registration: ClinicalTrials.gov number, NCT00932334.

\section{Introduction}

Living donor kidney transplantation (LDKT) yields superior outcomes in morbidity, mortality, and costs for patients with end-stage kidney disease compared to dialysis and deceased donor kidney transplantation. (1-6) Pre-emptive LDKT offers the most superior outcomes in cost, quality of life, and survival when compared to other treatments, including LDKT after prolonged hemodialysis.(7-9) Despite this, rates of pre-emptive LDKT are low, and disparities by race, income, and other factors are pervasive and have not improved despite evidence-based interventions. $(2,9,10)$ 
Knowledge is an important and modifiable factor associated with receipt of kidney transplants. Greater knowledge of kidney transplantation has been associated with increased completion of kidney transplant evaluations and readiness for kidney transplantation.(11-14) For this reason, the American Society of Transplantation and other organizations recommend providing tailored LDKT education to patients early in the pre-transplant process, with discussions regarding LDKT ideally when estimated glomerular filtration rate (eGFR) is $30 \mathrm{ml} / \mathrm{min} / 1.73 \mathrm{~m}^{2}$ or less.(15) LDKT-specific knowledge may help reduce barriers to LDKT among some potential recipients who have inaccurate perceptions of risks and costs.

Patients often receive information about LDKT from health professionals as well as through sharing information about LDKT with their family members or friends. $(11,16,17)$ To date however, studies have not evaluated the impact of receiving and sharing LDKT-specific information on LDKT knowledge among persons with chronic kidney disease (CKD). Studies examining associations between LDKT knowledge and information sharing could provide valuable insight into the mechanisms through which transplant candidates' knowledge could be increased. We studied the associations of receipt and sharing of information about LDKT with LDKT knowledge in a diverse population of adults with progressive CKD who were potentially eligible for pre-emptive LDKT. We hypothesized that patients' greater LDKT information receipt and sharing would be associated with greater LDKT knowledge.

\section{Methods}

We conducted secondary analyses of cross-sectional data obtained during the enrollment of participants in the Talking About Live Kidney Donation (TALK) Study. TALK was a randomized controlled trial (NCT009323334) conducted among 130 individuals with advanced CKD to study the effectiveness of educational and behavioral interventions to increase pursuit of pre-emptive LDKT from February 2009March 2011(18). All protocols and consent procedures were approved by The Johns Hopkins School of Medicine Institutional Review Board (IRB) in December 2008. The Duke University IRB approved all secondary data analyses for the present study.

\section{Study setting and participants}

The TALK study enrolled individuals with advanced progressive Stage 3-5 CKD who had not yet initiated kidney replacement therapy but were designated by their nephrologist as potential LDKT candidates. Participants were recruited from racially, ethnically, and socio-economically diverse community-based and academically affiliated nephrology practices in Baltimore, MD. Participants were between 18-70 years of age, had no evidence of end stage liver disease, unstable coronary artery disease, pulmonary hypertension, severe peripheral vascular disease, HIV, prior kidney replacement therapies (i.e. dialysis treatment or prior kidney transplant), stage IV congestive heart failure, cancer within 2 years prior to recruitment, or chronic debilitating infection. Participants were enrolled in the study after completing a screening telephone questionnaire. All TALK study participants completed a standard questionnaire at baseline, delivered via telephone by trained research assistants. These data were used for the present analyses. 


\section{Socio-demographic Characteristics}

Participants provided information about their age, sex, race (Black or African American, White, American Indian or Alaskan Native, Asian, two or more races, or other), highest level of education (Some high school, high school graduate or GED, two years of college, college, graduate or professional school), employment [retired/disabled or not retired/disabled (full-time employee, part-time employee, homemaker, unemployed/looking for work)], total annual household income ( $\leq \$ 20,000$ or $>\$ 20,000)$, and number of months and years seeing current nephrologist.

\section{Knowledge about LDKT}

We assessed participants' factual knowledge about LDKT by asking them to state whether 10 statements about LDKT were true or false (Table 1). For every correct answer, we assigned 1 point on a 10-point scale so that a score of 0 reflected no questions answered correctly and a score of 10 reflected all questions answered correctly. Missing, refused, and don't know answers were considered incorrect answers. The sum of correct answers was used as a measure of factual knowledge, with high knowledge defined as $\geq 8$ (median score) out of 10 possible correct answers.

\section{Information receipt and sharing about kidney treatment modalities}

Interviewers provided brief descriptions of dialysis, deceased donor kidney transplant, and LDKT and asked study participants whether they had previously received information about each treatment, and the last time such information was received (within the last week, month, year, or more than a year). Interviewers also asked participants to report how LDKT information was delivered to them, including via health professionals (i.e., doctor, nurse, social worker, clinic or class), or non-health professionals (i.e., family/friends, other patients, support group, or other sources). Responses were categorized as "did not receive information," "received information but not from health professionals," and "received information from health professionals." To assess participants' sharing of information, we asked, "Have you ever shared any information about LDKT with a family member or friend?" Responses were categorized as "did not receive information," received information but did not share," and "received and shared information."

\section{Statistical Analysis}

We described participants' sociodemographic characteristics both overall and according to their LDKT knowledge. Groups were compared using Mann-Whitney tests for continuous variables and Fisher's exact test for categorical variables. We used multivariable logistic regression models adjusted for age, race, and income to quantify the independent association of LDKT knowledge with LDKT information receipt, LDKT information receipt from health professionals, and LDKT information sharing, respectively. In post-hoc analyses, we used minimally adjusted logistic regression models to assess for interaction effects of race, income and sex on the association between LDKT information receipt and LDKT knowledge. 
All hypothesis tests were two-sided at a 0.05 significance level without multiple testing adjustment, and all analyses were performed using SAS software version 9.4 (SAS Institute, Cary) and R 4.0.2 (R Core Team, Vienna, Austria).

\section{Results}

\section{Participant Socio-demographic Characteristics and LDKT knowledge}

Among the 130 participants, the median (IQR) age was 59.5 (52.0-65.0) years. A majority (60\%) of participants identified as female. Nearly half (48\%) of participants described their race as Black or African American. Half (51\%) of participants reported at least two years of college education, and a third (35\%) described themselves as full- or part-time employees. Many $(27 \%)$ reported an annual household income less than $\$ 20,000$. Individuals had been seeing their current nephrologist for a median (IQR) of 2.0 (1.04.0) years. (Table 2)

Overall, participants' LDKT knowledge was high [median (interquartile range (IQR)) of 8 (7-9) out of 10]. Those with higher incomes $(>\$ 20,000)$ were more likely to have high knowledge than those with lower incomes $(\leq \$ 20,000)$, and median months in nephrology care was higher among those with high knowledge compared to those with lower knowledge. LDKT knowledge did not significantly differ according to participants' other sociodemographic characteristics. (Table 2)

\section{LDK Information receipt and LDKT information sharing}

Among all participants, only one third $(33 \%, n=43)$ reported having received information about LDKT (Table 3), while less than one half reported having received information about transplant in general $(44 \%, n=57)$, and the majority reported having received information about dialysis ( $59 \% ; n=77)$. Among the 43 participants who reported having received LDKT information, almost half $(44 \% ; n=19)$ reported they last received the information within the last year (versus within last week, month, or over a year ago). Nearly a quarter $(25 \% ; n=32)$ of all participants reported having received LDKT information from health professionals, while fewer reported receiving information that was not from health care professionals (e.g., family/friends, other patients, support group, or other sources $(9 \% ; n=11)$. Participants most frequently received information from a doctor $(23 \% ; n=30)$, followed by a nurse $(11 \% ; n=14)$, a class $(7 \%$; $n=9)$, a social worker $(5 \% ; n=6)$, and a clinic $(5 \% ; n=6)$. Among non-health care professionals, participants primarily received information from books pamphlets or brochures $(22 \%, n=28)$, from family or friends $(15 \%, n=20)$, followed by other patients $(11 \%, n=14)$, and other sources. A majority of individuals did not receive LDKT information $(67 \%, n=87)$, and only $28 \%(n=37)$ of participants received and shared LDKT information with family or friends.

\section{Association of LDKT knowledge with information receipt about LDKT}

Participants who reported they had received LDKT information were more likely to have high knowledge compared to those who had not received LDKT information ( $77 \%$ versus $45 \%$, respectively). Similarly, 
those who reported they received LDKT information from healthcare professionals were more likely to have high knowledge compared those who received LDKT information from other sources (81\% versus $64 \%$, respectively) and those who did not receive LDKT information at all ( $81 \%$ versus $45 \%$, respectively). Individuals who reported they received information about LDKT and shared that information with family and friends were more likely to have high knowledge than those who reported they had not received LDKT information at all ( $76 \%$ versus $45 \%$, respectively).

In multivariable logistic regression models (Table 4) adjusting for participants' age, race and total household income, participants who received and shared LDKT information had three-fold higher odds of high LDKT knowledge compared to those who did not receive information (OR [95\% Cl] 3.05 [1.24-8.08]). Individuals who received LDKT information (versus those who did not receive information) from health professionals also had higher odds of high LDKT knowledge (OR [95\% Cl] 4.01 [1.49-12.18]).

In post-hoc analyses, we did not find any statistically significant interaction effects of race, income, or sex on the association between LDKT information receipt and LDKT knowledge (results not shown).

\section{Discussion}

In this study of individuals with CKD who were deemed to be candidates for pre-emptive LDKT by their nephrologists, only one-third of participants reported they had received information about LDKT, while over half had received information about dialysis. Those who received LDKT information from health care providers and those who received and shared LDKT information with family and friends had higher odds of high LDKT knowledge. These findings suggest efforts to improve LDKT-specific information delivery and sharing are needed and could enhance LDKT knowledge, which has been shown to be important in improving access to LDKT.

To our knowledge, this is one of the first studies to examine the association of LDKT information receipt or sharing with LDKT knowledge among potential pre-emptive LDKT candidates. LDKT knowledge has mainly been studied among individuals requiring kidney replacement therapy. For example, Waterman et al. investigated approaches to patient centered transplant education through surveys of dialysis staff and found that only $35 \%$ of units had detailed discussions about LDKT benefits. Our findings build on this by providing salient evidence regarding the potential role of earlier transplant related education delivery (i.e., in progressive advanced CKD). They also highlight the potential importance of delivery of information by health care providers and the subsequent involvement of family members or friends in LDKT information sharing as a mechanism for identifying and reducing barriers to LDKT. $(16,19)$ Consistent with prior studies, participants' self-reported receipt of LDKT specific information was low.(11, 20) Our findings suggest that efforts to improve information delivery between physicians and patients could enhance their likelihood of having access to LDKT. The additional discussions or exploration patients may undertake with family or friends after receiving information about LDKT might also be helpful in gaining and reinforcing LDKT knowledge, especially if it is tailored to describe processes involved in pursuit of 
transplant, and associated risks and benefits $(21,22)$. Studies should also explore barriers to earlier delivery of information to potential LDKT candidates.

We did not observe statistically significant interactions with regard to differences in the associations of information receipt or sharing and knowledge on the basis of race, sex, or income. Yet, a disproportionately higher percentage of individuals with an income of less than or equal to $\$ 20,000$ had lower LDKT knowledge. Potential LDKT candidates with low income may face numerous barriers to obtaining LDKT knowledge, including lack of access to information sources or poorer access to health care professionals. Interventions addressing these structural barriers to information receipt could improve LDKT knowledge for these individuals.

While our study explored the potential role of delivery of LDKT information from various types of health care providers, we did not evaluate whether other trusted non-health professional networks (e.g., community members, lay educators, and peer navigators) might also be important. Delivery of information through non-health professional networks could augment existing evidence-based interventions including interventions delivered in non-clinical/home-based settings or interventions that address social barriers to the transplant process,(21-25) including a range of social factors that disproportionately burden groups impacted by substantial LDKT disparities (e.g., self-described Black or African American individuals).(26-29)

Limitations of this study merit attention. First, participants were recruited from nephrology practices from a single, yet ethnically/racially diverse metropolitan region. Findings might differ among other populations from other geographic regions. Second, participants' self-reports of receipt of information might not reflect their actual receipt of information. Still, participants' recollection of receiving information may be the most important indicator that information delivery has been effective. Third, the crosssectional design of the study also limits the ability to establish causal associations. Future longitudinal studies should evaluate whether information receipt from a number of sources or information sharing with various individuals may influence LDKT knowledge. Finally, data were collected in 2011, and practices regarding LDKT education could have evolved since then, including the use of various media forms in transmitting knowledge and information regarding transplant. Despite this, studies show that rates of LDKT have been stagnant over decades and race disparities in LDKT have worsened (2). Nonetheless, our findings provide important insights contributing to efforts to improve LDKT rates.

\section{Conclusions}

In this study of pre-kidney replacement individuals with advanced CKD, LDKT information receipt was low when compared to information receipt for dialysis. Individuals who reported receiving LDKT information from health professionals or receiving and sharing information about LDKT among family/friends had statistically significantly higher odds of high LDKT knowledge. Continued efforts to improve LDKT knowledge through information delivery and by encouraging information sharing among potential recipients and family/friends are needed and could help efforts to improve access to LDKT. 


\section{Declarations}

\section{Ethics approval and consent to participate}

The study protocol was approved by The Johns Hopkins School of Medicine Institutional Review Board (IRB) in December 2008. The Duke University IRB approved all secondary data analyses for the present study. All patients signed informed consent to participate in the study.

\section{Consent for publication}

Not applicable

\section{Competing interests}

The authors declare that they have no competing interests.

\section{Contributions}

Conception and design of the study (DM, LEB, JP, HL, CD), data collection (NDP, PE), statistical analysis $(C D, H L, J P$ ), interpretation of the data (LEB, DM, CD, HL, JP, NDP, LM, PE, AC, TB), article writing (DM, LEB), manuscript review and modification (all authors). All authors read and approved the final version of the manuscript.

\section{Funding}

DM and LM were supported by the Duke Center for Research to Advance Healthcare Equity (REACH Equity), which is supported by the National Institute on Minority Health and Health Disparities under award number U54MD012530.

\section{Acknowledgements}

Not applicable.

\section{Availability of data and materials}

The datasets used and/or analyzed during the current study are available from the corresponding author on reasonable request.

\section{References}


1. Kasiske BL, Snyder JJ, Matas AJ, Ellison MD, Gill JS, Kausz AT. Preemptive kidney transplantation: the advantage and the advantaged. J Am Soc Nephrol. 2002;13(5):1358-64.

2. Purnell TS, Luo X, Cooper LA, Massie AB, Kucirka LM, Henderson ML, et al. Association of Race and Ethnicity With Live Donor Kidney Transplantation in the United States From 1995 to 2014. Jama. 2018;319(1):49-61.

3. Waterman AD, Rodrigue JR, Purnell TS, Ladin K, Boulware LE. Addressing racial and ethnic disparities in live donor kidney transplantation: priorities for research and intervention. Semin Nephrol. 2010;30(1):90-8.

4. Terasaki PI, Cecka JM, Gjertson DW, Takemoto S. High survival rates of kidney transplants from spousal and living unrelated donors. The New England journal of medicine. 1995;333(6):333-6.

5. Boulware LE, Hill-Briggs F, Kraus ES, Melancon JK, Senga M, Evans KE, et al. Identifying and addressing barriers to African American and non-African American families' discussions about preemptive living related kidney transplantation. Progress in transplantation (Aliso Viejo, Calif). 2011;21(2):97-104; quiz 5.

6. Purnell TS, Auguste P, Crews DC, Lamprea-Montealegre J, Olufade T, Greer R, et al. Comparison of life participation activities among adults treated by hemodialysis, peritoneal dialysis, and kidney transplantation: a systematic review. Am J Kidney Dis. 2013;62(5):953-73.

7. Kasiske BL, Snyder JJ, Matas AJ, Ellison MD, Gill JS, Kausz AT. Preemptive Kidney Transplantation: The Advantage and the Advantaged. Journal of the American Society of Nephrology. 2002;13(5):1358.

8. Kim HY, Choi JY, Kwon HW, Jung JH, Han M, Park S-K, et al. Comparison of Clinical Outcomes Between Preemptive Transplant and Transplant After a Short Period of Dialysis in Living-Donor Kidney Transplantation: A Propensity-Score-Based Analysis. Ann Transplant. 2019;24:75-83.

9. Jay CL, Dean PG, Helmick RA, Stegall MD. Reassessing Preemptive Kidney Transplantation in the United States: Are We Making Progress? Transplantation. 2016;100(5):1120-7.

10. Purnell TS, Crews DC. Persistent Disparities in Preemptive Kidney Transplantation. Clin J Am Soc Nephrol. 2019;14(10):1430-1.

11. Waterman AD, Peipert JD, Hyland SS, McCabe MS, Schenk EA, Liu J. Modifiable patient characteristics and racial disparities in evaluation completion and living donor transplant. Clin $\mathrm{J} \mathrm{Am}$ Soc Nephrol. 2013;8(6):995-1002.

12. Kutner NG, Zhang R, Huang Y, Johansen KL. Impact of race on predialysis discussions and kidney transplant preemptive wait-listing. American journal of nephrology. 2012;35(4):305-11.

13. Boulware LE, Meoni LA, Fink NE, Parekh RS, Kao WH, Klag MJ, et al. Preferences, knowledge, communication and patient-physician discussion of living kidney transplantation in African American families. Am J Transplant. 2005;5(6):1503-12.

14. Rodrigue JR, Paek MJ, Egbuna O, Waterman AD, Schold JD, Pavlakis M, et al. Readiness of waitlisted black patients to pursue live donor kidney transplant. Progress in transplantation (Aliso Viejo, Calif). 2014;24(4):355-61. 
15. Waterman AD, Morgievich M, Cohen DJ, Butt Z, Chakkera HA, Lindower C, et al. Living Donor Kidney Transplantation: Improving Education Outside of Transplant Centers about Live Donor Transplantation-Recommendations from a Consensus Conference. Clin J Am Soc Nephrol. 2015;10(9):1659-69.

16. Waterman AD, Peipert JD, McSorley A-M, Goalby CJ, Beaumont JL, Peace L. Direct Delivery of Kidney Transplant Education to Black and Low-Income Patients Receiving Dialysis: A Randomized Controlled Trial. American Journal of Kidney Diseases. 2019.

17. Gupta N, Salter ML, Garonzik-Wang JM, Reese PP, Wickliffe CE, Dagher NN, et al. Actual and perceived knowledge of kidney transplantation and the pursuit of a live donor. Transplantation. 2014;98(9):969-73.

18. Boulware LE, Hill-Briggs F, Kraus ES, Melancon JK, Falcone B, Ephraim PL, et al. Effectiveness of educational and social worker interventions to activate patients' discussion and pursuit of preemptive living donor kidney transplantation: a randomized controlled trial. Am J Kidney Dis. 2013;61(3):476-86.

19. Patzer RE, McPherson L, Redmond N, DuBay D, Zayas C, Hartmann E, et al. A Culturally Sensitive Website-based Intervention to Improve Living Donor Kidney Transplant Among African Americans. Kidney International Reports. 2019.

20. Finkelstein FO, Story K, Firanek C, Barre P, Takano T, Soroka S, et al. Perceived knowledge among patients cared for by nephrologists about chronic kidney disease and end-stage renal disease therapies. Kidney Int. 2008;74(9):1178-84.

21. Boulware LE, Hill-Briggs F, Kraus ES, Melancon JK, Falcone B, Ephraim PL, et al. Effectiveness of Educational and Social Worker Interventions to Activate Patients' Discussion and Pursuit of Preemptive Living Donor Kidney Transplantation: A Randomized Controlled Trial. Am J Kidney Dis. 2013;61(3):476-86.

22. Boulware LE, Ephraim PL, Ameling J, Lewis-Boyer L, Rabb H, Greer RC, et al. Effectiveness of informational decision aids and a live donor financial assistance program on pursuit of live kidney transplants in African American hemodialysis patients. BMC Nephrol. 2018;19(1):107.

23. Rodrigue JR, Pavlakis M, Egbuna O, Paek M, Waterman AD, Mandelbrot DA. The "House Calls" Trial: A Randomized Controlled Trial to Reduce Racial Disparities in Live Donor Kidney Transplantation: Rationale and Design. Contemporary clinical trials. 2012;33(4):811-8.

24. Tan JC, Gordon EJ, Dew MA, LaPointe Rudow D, Steiner RW, Woodle ES, et al. Living Donor Kidney Transplantation: Facilitating Education about Live Kidney Donation-Recommendations from a Consensus Conference. Clin J Am Soc Nephrol. 2015;10(9):1670-7.

25. Rudow DL, Hays R, Baliga P, Cohen DJ, Cooper M, Danovitch GM, et al. Consensus Conference on Best Practices in Live Kidney Donation: Recommendations to Optimize Education, Access, and Care. Am J Transplant. 2015;15(4):914-22.

26. Harding K, Mersha TB, Vassalotti JA, Webb FA, Nicholas SB. Current State and Future Trends to Optimize the Care of Chronic Kidney Disease in African Americans. American journal of nephrology. 
2017;46(2):176-86.

27. Norton JM, Moxey-Mims MM, Eggers PW, Narva AS, Star RA, Kimmel PL, et al. Social Determinants of Racial Disparities in CKD. J Am Soc Nephrol. 2016;27(9):2576-95.

28. Boulware LE, Troll MU, Plantinga LC, Powe NR. The association of state and national legislation with living kidney donation rates in the United States: a national study. Am J Transplant. 2008;8(7):145170.

29. Powe NR, Boulware LE. The uneven distribution of kidney transplants: getting at the root causes and improving care. Am J Kidney Dis. 2002;40(4):861-3.

\section{Tables}

Table 1: LDKT Questions and answers

\begin{tabular}{|c|c|}
\hline Question & Answer \\
\hline A living person who gives you a kidney must be related to you & False \\
\hline $\begin{array}{l}\text { There are enough kidneys from people who have passed away to provide everyone who } \\
\text { needs a kidney transplant with a kidney }\end{array}$ & False \\
\hline $\begin{array}{l}\text { Getting a kidney from a living person is the best treatment option for most people whose } \\
\text { kidneys have failed }\end{array}$ & True \\
\hline A person can live a normal life with only one kidney & True \\
\hline $\begin{array}{l}\text { A person can get a kidney from their family member even if the family member has HIV } \\
\text { or hepatitis }\end{array}$ & $\begin{array}{l}\text { False at } \\
\text { time of } \\
\text { survey }\end{array}$ \\
\hline $\begin{array}{l}\text { If you receive a kidney transplant, Medicare or government insurance will cover most } \\
\text { medical costs for the kidney transplant for the rest of your life }\end{array}$ & $\begin{array}{l}\text { False at } \\
\text { time of } \\
\text { survey }\end{array}$ \\
\hline $\begin{array}{l}\text { If a living person gives you one of their kidneys for a kidney transplant, Medicare or } \\
\text { government insurance will cover most of that person's medical costs related to the } \\
\text { kidney transplant }\end{array}$ & True \\
\hline $\begin{array}{l}\text { After a living person gives you their kidney, Medicare or government insurance will } \\
\text { continue to cover that person's medical costs for the rest of their life }\end{array}$ & False \\
\hline People need to take medications after getting a kidney transplant & True \\
\hline $\begin{array}{l}\text { After a kidney transplant if a person misses or doesn't take } 1 \text { day of their medicine, the } \\
\text { new kidney will not work }\end{array}$ & False \\
\hline
\end{tabular}

Table 2: Demographic characteristics by high and lower LDKT knowledge 


\begin{tabular}{|c|c|c|c|c|}
\hline & Overall & $\begin{array}{l}\text { Lower } \\
\text { knowledge } \\
\text { (<8 pts) }\end{array}$ & $\begin{array}{l}\text { High } \\
\text { knowledge } \\
\text { ( } \geq 8 \text { pts) }\end{array}$ & $P$ \\
\hline $\mathrm{n}$ & 130 & 58 & 72 & \\
\hline age Median [IQR] & $\begin{array}{l}59.5[52- \\
65]\end{array}$ & $61[53.2-65.8]$ & $59[50.8-65]$ & 0.17 \\
\hline Sex & & & & 0.86 \\
\hline Female & $78(60)$ & $34(43.6)$ & $44(56.4)$ & \\
\hline Male & $52(40)$ & $24(46.2)$ & $28(53.8)$ & \\
\hline Race & & & & 0.23 \\
\hline American Indian or Alaskan Native & $1(0.8)$ & $0(0)$ & $1(100)$ & \\
\hline Asian & $1(0.8)$ & $1(100)$ & $0(0)$ & \\
\hline Black or African American & $62(47.7)$ & $29(46.8)$ & $33(53.2)$ & \\
\hline White & $60(46.2)$ & $24(40)$ & $36(60)$ & \\
\hline Two or more races & $3(2.3)$ & $1(33.3)$ & $2(66.7)$ & \\
\hline Other & $3(2.3)$ & $3(100)$ & $0(0)$ & \\
\hline Black or African American & & & & 0.72 \\
\hline No & $68(52.3)$ & $29(42.6)$ & $39(57.4)$ & \\
\hline Yes & $62(47.7)$ & $29(46.8)$ & $33(53.2)$ & \\
\hline Education & & & & 0.96 \\
\hline Some high school (9-12) & $24(18.5)$ & $12(50)$ & $12(50)$ & \\
\hline HS grad/GED & $40(30.8)$ & $17(42.5)$ & $23(57.5)$ & \\
\hline 2 years of college & $20(15.4)$ & $8(40)$ & $12(60)$ & \\
\hline College & $25(19.2)$ & $12(48)$ & $13(52)$ & \\
\hline Graduate or prof school & $21(16.2)$ & $9(42.9)$ & $12(57.1)$ & \\
\hline Education & & & & $>0.99$ \\
\hline High school or less & $64(49.2)$ & $29(45.3)$ & $35(54.7)$ & \\
\hline Some college or more & $66(50.8)$ & $29(43.9)$ & $37(56.1)$ & \\
\hline Major activity & & & & 0.43 \\
\hline Full-time employee & $34(26.2)$ & $14(41.2)$ & $20(58.8)$ & \\
\hline
\end{tabular}




\begin{tabular}{|c|c|c|c|c|}
\hline Part-time employee & $12(9.2)$ & $6(50)$ & $6(50)$ & \\
\hline Retired & $35(26.9)$ & $14(40)$ & $21(60)$ & \\
\hline Homemaker & $12(9.2)$ & $3(25)$ & $9(75)$ & \\
\hline Disabled & $31(23.8)$ & $17(54.8)$ & $14(45.2)$ & \\
\hline Unemployed/Looking for work & $6(4.6)$ & $4(66.7)$ & $2(33.3)$ & \\
\hline Major activity & & & & 0.60 \\
\hline Retired/disabled & $66(50.8)$ & $31(47)$ & $35(53)$ & \\
\hline Not retired/disabled & $64(49.2)$ & $27(42.2)$ & $37(57.8)$ & \\
\hline Annual household income & & & & 0.14 \\
\hline$\$ 0-\$ 20,000$ & $35(26.9)$ & $21(60)$ & $14(40)$ & \\
\hline$\$ 20,001-\$ 40,000$ & $20(15.4)$ & $7(35)$ & $13(65)$ & \\
\hline$\$ 40,001-\$ 60,000$ & $25(19.2)$ & $8(32)$ & $17(68)$ & \\
\hline$\$ 60,001-\$ 80,000$ & $9(6.9)$ & $3(33.3)$ & $6(66.7)$ & \\
\hline$\$ 80,001-\$ 100,000$ & $9(6.9)$ & $4(44.4)$ & $5(55.6)$ & \\
\hline Over $\$ 100,000$ & $23(17.7)$ & $8(34.8)$ & $15(65.2)$ & \\
\hline REFUSED & $5(3.8)$ & $4(80)$ & $1(20)$ & \\
\hline DON'T KNOW & $4(3.1)$ & $3(75)$ & $1(25)$ & \\
\hline Annual household income & & & & $<0.01$ \\
\hline$\$ 0-\$ 20,000$ & $35(26.9)$ & $21(60)$ & $14(40)$ & \\
\hline Over $\$ 20,000$ & $86(66.2)$ & $30(34.9)$ & $56(65.1)$ & \\
\hline REFUSED/DON'T KNOW & $9(6.9)$ & $7(77.8)$ & $2(22.2)$ & \\
\hline $\begin{array}{l}\text { Months in nephrology care Median } \\
\text { [IQR] }\end{array}$ & $24[12-48]$ & $14[10-36]$ & $24[12-51]$ & 0.04 \\
\hline LDKT knowledge score & & & & - \\
\hline Mean (SD) & $7.5(1.5)$ & $6.2(1.1)$ & $8.6(0.6)$ & \\
\hline Median [IQR] & $8[7-9]$ & $6[6-7]$ & $8[8-9]$ & \\
\hline (Min, Max) & $(1,10)$ & $(1,7)$ & $(8,10)$ & \\
\hline
\end{tabular}

Table 3: Receipt, type, and mode of information by level of knowledge 


\begin{tabular}{|c|c|c|c|c|}
\hline & Overall & $\begin{array}{l}\text { Lower } \\
\text { knowledge } \\
\text { (<8 pts) }\end{array}$ & $\begin{array}{l}\text { High } \\
\text { knowledge } \\
\text { ( } \geq 8 \text { pts) }\end{array}$ & $P$ \\
\hline $\mathrm{n}$ & 130 & 58 & 72 & \\
\hline \multicolumn{5}{|l|}{$\begin{array}{l}\text { Receipt of information about dialysis, kidney } \\
\text { transplant, and LDKT }\end{array}$} \\
\hline Have you ever gotten information about LDKT? & & & & $<0.01$ \\
\hline No & $\begin{array}{l}87 \\
(66.9)\end{array}$ & $48(55.2)$ & $39(44.8)$ & \\
\hline Yes & $\begin{array}{l}43 \\
(33.1)\end{array}$ & $10(23.3)$ & $33(76.7)$ & \\
\hline $\begin{array}{l}\text { Have you ever gotten information about kidney } \\
\text { transplant? }\end{array}$ & & & & $<0.01$ \\
\hline No & $\begin{array}{l}73 \\
(56.2)\end{array}$ & $41(56.2)$ & $32(43.8)$ & \\
\hline Yes & $\begin{array}{l}57 \\
(43.8)\end{array}$ & $17(29.8)$ & $40(70.2)$ & \\
\hline Have you ever gotten information about dialysis? & & & & 0.03 \\
\hline No & $\begin{array}{l}53 \\
(40.8)\end{array}$ & $30(56.6)$ & $23(43.4)$ & \\
\hline Yes & $\begin{array}{l}77 \\
(59.2)\end{array}$ & $28(36.4)$ & $49(63.6)$ & \\
\hline \multicolumn{5}{|l|}{ Receipt of LDKT information } \\
\hline Last time received information about LDKT & & & & 0.01 \\
\hline Within the last week & $9(6.9)$ & $2(22.2)$ & $7(77.8)$ & \\
\hline Within the last month & $6(4.6)$ & $2(33.3)$ & $4(66.7)$ & \\
\hline Within the last year & $\begin{array}{l}19 \\
(14.6)\end{array}$ & $4(21.1)$ & $15(78.9)$ & \\
\hline More than 1 year ago & $9(6.9)$ & $2(22.2)$ & 7 (77.8) & \\
\hline Never & $\begin{array}{l}87 \\
(66.9)\end{array}$ & $48(51.2)$ & $39(44.8)$ & \\
\hline $\begin{array}{l}\text { Healthcare professionals sources of LDKT } \\
\text { information }\end{array}$ & & & & - \\
\hline Doctor & $\begin{array}{l}30 \\
(23.1)\end{array}$ & $6(20)$ & $24(80)$ & \\
\hline Nurse & 14 & $4(28.6)$ & $10(71.4)$ & \\
\hline
\end{tabular}




$\begin{array}{llll}\text { Social worker } & 6(4.6) & 1(16.7) & 5(83.3) \\ \text { Clinic } & 6(4.6) & 1(16.7) & 5(83.3) \\ \text { Class } & 9(6.9) & 1(11.1) & 8(88.9)\end{array}$

Non-healthcare professionals sources of information (i.e., all other sources)

Computer

Educational video

Radio

Magazine

Books, pamphlets, or brochure

Family or friends

Other patients

Support group

Any other source

Receipt of LDKT information from healthcare professionals

Did not receive LDKT info

Received LDKT info, but not from healthcare professionals

Received LDKT info from healthcare professionals

Shared LDKT information

Did not receive LDKT info

Received LDKT info, but did not share

Received LDKT info and shared

Shared LDKT information
Did not receive LDKT info
Received LDKT info, but did not share
Received LDKT info and shared

12

(9.2)

9 (6.9) $2(22.2)$

$2(1.5) \quad 1(50)$

$3(30)$

10
$(7.7)$

28

(21.5)

$5(17.9)$

20

(15.4)

$5(25)$

14

(10.8)

$4(28.6)$

$10(71.4)$

$4(3.1) \quad 2(50)$

$2(50)$

$8(6.2) \quad 2(25)$

$6(75)$

7 (77.8)

$1(50)$

7 (70)

$23(82.1)$

$15(75)$

(6.)

\section{7}

(66.9)

11

(8.5)

32

(24.6)

48 (55.2)

$39(44.8)$

$24.6)$

4 (36.4)

7 (63.6)

6 (18.8)

26 (81.2)

\begin{tabular}{llll}
87 & $48(55.2)$ & $39(44.8)$ & $<0.01$ \\
$(66.9)$ & & \\
$6(4.6)$ & $1(16.7)$ & $5(83.3)$ \\
37 & $9(24.3)$ & $28(75.7)$ \\
$(28.5)$ & & & \\
\hline
\end{tabular}


Table 4: Association of LDKT information receipt, delivery modality, and sharing with LDKT knowledge

Type of information receipt (LDKT)

Models for receipt of information

Did not receive info

Received info

Models for receipt and sharing of information

Did not receive info

Received but did not share

Received and shared

Models for receipt of information from $\mathrm{HC}$ professional versus non- $\mathrm{HC}$ professional

Did not receive info

Received but not from $\mathrm{HC}$ prof

Received from $\mathrm{HC}$ prof
Adjusted odds ratios of high LDKT

knowledge (95\% confidence intervals)

(ref)

$3.27(1.39,8.21)$

(ref)

$4.98(0.74,98.63)$

$3.05(1.24,8.08)$

(ref)

$2.08(0.54,9.14)$

$4.01(1.49,12.18)$ 